\title{
Neuropathic Pain Following Nerve Injury
}

\author{
Stanislava Jergova ${ }^{1,2}$ \\ ${ }^{1}$ University of Miami, Florida \\ 2Institute of Neurobiology, Slovak Academy of Science \\ 1 USA \\ 2Slovakia
}

\section{Introduction}

Pain is essential for our wellbeing as it warns us from possible injuries. After injury, pain sensations around injured tissue lead to protective behavior and so indirectly contribute to a faster healing process. Physiological pain is usually acute or subchronic, it progressively diminishes in the process of healing and responds to conventionally used analgesics. However, injury to the somatosensory system may give rise to ongoing pain that persists beyond the healing process of the original injury and is refractory to analgesics. Such pain is termed neuropathic. Neuropathic pain negatively influences quality of life of patients and often interferes with the rehabilitation strategies after nerve injury. Pharmacological treatment or surgical intervention provide only short term alleviation, since adverse effects such as drug tolerance and addictions, motor deficit and worsening pain may emerge over time. Therefore there is a need to identify novel, more effective long term therapies. Cell transplantation and gene therapy present target-oriented therapies minimizing side effects of medication due their local action. Therefore they are promising way to manage chronic neuropathic pain.

\section{Anatomy of pain}

Stimuli coming from our environment are perceived by peripheral receptors. Each receptor is highly specialized to recognize specific range of mechanical, thermal and chemical stimuli and their intensity. Receptors transform stimuli into a membrane depolarization of primary sensory neurons and the information is propagated by afferent fibers as a train of action potentials to the spinal cord. Depolarization of primary afferent fibers terminations in the spinal cord induce release of neurotransmitters that influence excitability of second order neurons and the information is transferred to the supraspinal centers. Noxious sensations were originally explained as an intensity-dependent activation of primary afferent fibers encoding non-noxious stimuli. The existence of specific receptors activated only by the noxious stimuli was first suggested by Sherington in 1906 (Sherington, 1906, as cited in (McMahon \& Koltzenburg, 2005)) and later validated by Perl (1967) (Burges \& Perl, 1967, as cited in (McMahon \& Koltzenburg, 2005)).

Primary afferent fibers are classified into several groups based on their myelin ensheatment, size and the conduction velocity. Large, myelinated and rapid conducting $A \alpha / \beta$ are 
activated by non-noxious mechanical stimuli, A $\delta$ fibers mediates thermal and noxious sensations. Small, unmyelinated, slow conducting C fibers are primarily nociceptive. Nociceptors as specialized receptors of noxious stimuli are free nerve endings of $C$ and $A \delta$ fibers. However, low threshold mechanoreceptors $A \beta$ are suggested to play a role in the development of chronic pain. The neuronal bodies of the primary afferent fibers are located in dorsal root ganglia (DRGs). Morphologically they are divided into three groups: large diameter and medium diameter myelinated cells, and small diameter unmyelinated cells presumptive to $A \delta, A \beta$ and $A \delta / C$ fibers respectively. Small and medium diameter cells are classified as nociceptors and therefore have been extensively studied in pain research. These cells can be subdivided into two broad classes based on their neurochemical properties; peptidergic neurons contain neuropeptides as substance $\mathrm{P}$ and calcitonin gene-related peptide and express receptors for nerve growth factor. Nonpeptidergic are responsive to glial cell line-derived neurotrophic factors and have binding site for isolectin IB4 obtained from Bandeiraea simplicifolia. However, it is not clear if such morphological differences correspond to different functional types, as for example heat activated capsaicin receptor is expressed in both peptidergic and nonpeptidergic neuronal classes (Guo et al., 1999; Michael \& Priestley, 1999). Primary afferent fibers terminate in the various levels of dorsal horn. Termination reflects physiological property of a stimulus and its anatomical location. Superficial laminae are primary termination of the nociceptive primary afferents. However neurons in deeper laminae also play a role in the pain processing, especially during chronic pain states.

\section{Mechanisms of neuropathic pain}

Neuropathic pain presents a paradox outcome of the injury to the somatosensory nervous system, as one could expect reduction of sensations coming from the denervated area. However, there are substantial qualitative changes in the processing of nociceptive information after nerve injury that lead to a persistent pain. The prevalence of neuropathic pain is around 5-8 \% in the general population (Daousi et al., 2004) and with insufficient pharmacological treatment it represents a serious medical problem. There is a wide range of injuries and diseases causing neuropathic pain, such as diabetic neuropathy, surgical lesions, multiple sclerosis, spinal cord injury and a stroke. This diversity of clinical conditions related to the neuropathic pain makes it difficult to identify a common mechanism. Moreover, neuropathic pain does not necessarily develop in every patient even when the etiology is very similar, and symptoms within the same etiology may vary substantially between patients.

The major hallmark of neuropathic pain is presence of mechanical and cold hyperalgesia and allodynia. Heat hyperalgesia is reported in fewer cases. Mechanical allodynia as a touch evoked pain is the major reason for suffering of neuropathic pain patients. This pain accompanies inflammatory and neuropathic conditions. There are evidences that under both conditions this extreme sensitivity is not elicited by nociceptors but by myelinated low threshold $A \beta$ mechanoreceptors, that normally encode non-painful stimuli. The ability of $A \beta$ fibers to evoke painful sensations is caused by profound alterations of central pain processing (Klede et al., 2003; Koppert et al., 2001). The other disturbances in sensitivity to mechanical stimuli are caused by an excitation of A $\delta$ fibers (pin-prick hyperalgesia) (Ziegler et al., 1999) or the expansion of the receptive field of nociceptors (blunt pressure 
hyperalgesia) (Reeh et al., 1987). Hypersensitivity to cold is prominent after traumatic nerve injuries (Wahren \& Torebjork, 1992). The mechanisms of cold hyperalgesia involve changes in the peripheral and central processing of thermal stimuli. A mechanism of heat hyperalgesia is assumed to involve sensitized unmyelinated nociceptors.

\subsection{Peripheral changes in neuropathic pain}

The mechanisms underlying neuropathic pain involve complex pathophysiological changes in the processing of sensory signals. Changes in the neuronal excitability, discharges generated along the nerve fiber, changes in the gene expression and up- or down-regulation of neurotransmitter release, all those contribute to the prolonged hypersensitivity after nerve injury. A brief characteristic of these changes and their impact on the chronic pain development are outlined below.

\subsubsection{Ectopic discharges}

When the axon loses the connection with the target tissue after traumatic nerve injury or a disease, retrograde transport of vital growth factors (such as fibroblast growth factor and nerve growth factor) to the cell body is disrupted. While in neonates this leads to the death of sensory neurons, in adults a disruption of neurotrophic support causes changes in the neurochemical and electrical properties of sensory neurons. The most important consequence of this phenotypic switch is the development of spontaneous discharges. Spontaneous discharges are generated not at the usual place, i.e. at the termination of primary afferent fibers in the dorsal horn, but rather in the injured area-in the stump of injured nerve, in the corresponding sensory neurons in DRG and the neighboring intact afferents. Stump is formed at the proximal end of transected axon. It gives rise to fine sprouting fibers in the process of regeneration. These sprouts may elongate and reach the target tissue or, in the case of blocked growth (such as after limb amputation), the sprouts form end-bulb neuroma. The presence of spontaneous discharges arising from the neuroma was reported in 1974 by Wall and Gutnic (Wall \& Gutnick, 1974, as cited in (McMahon \& Koltzenburg, 2005)) in the model of sciatic nerve axotomy and later it was confirmed in other forms of nerve injury, including diabetic polyneuropathy (Dobretsov et al., 2001) and viral infection (Kress \& Fickenscher, 2001).

Ectopic discharges may arise not only from axotomized fibers but also from partially injured nerves. The local inflammation and demyelination after nerve injury has been shown to contribute to spontaneous firing in the spared nerve fibers after incomplete axotomy (Kajander \& Bennett, 1992; Tal \& Eliav, 1996). Other sources of firing are intact axons in close proximity of the injured ones. In the experiments where spinal nerve L5 was transected, ectopic discharges have been recorded from uninjured L4 nerve. These uninjured axons are exposed to a soup of inflammatory mediators such as cytokines and growth factors released by degenerating axon and surrounding tissue. Although there is no direct evidence that such firing elicit hypersensitivity in the area innervated by uninjured axons, their increased excitability may contribute to the development of central sensitization (Ali et al., 1999; Wu et al., 2001). The sensory neurons in the DRG affected by the nerve injury are another source of ectopic activity, especially if the injury is proximal to dorsal root ganglia (Liu et al., 2000) such as during intervertebrae disc herniation. Clinical studies showed that ectopic discharges are correlated with the manifestation of spontaneous pain states and that 
both are transiently reduced by drugs that eliminate discharges (Campero et al., 1998; Orstavik et al., 2003). The ectopic firing also causes a neurogenic inflammation seen in patients with complex regional pain syndrome. The antidromic propagation of a signal in a nerve fiber during ectopic firing causes stimulation of peripheral nerve endings and subsequent release of neurotransmitter such as SP and calcitonin gene-related peptide. Their vasodilatation activity causes swelling and redness of the innervated tissue, characteristic for causalgia (McMahon \& Koltzenburg, 2005).

\subsubsection{Relationship of ectopic discharges to hypersensitivity}

When the intensity of peripheral stimulus reaches a certain threshold, peripheral receptors respond with discharges and the signal is propagated to the central nervous system (CNS). In the presence of ectopic activity, discharges are elicited by subthreshold stimulus in the process of peripheral sensitization. Moreover, discharges may persist beyond the end of the stimulation. The afterdischarges are generated due to self-sustained activity of ectopic sites and act as signal amplifiers. The subthreshold stimulus can therefore elicit greater-thannormal response.

Peripheral nerves with ectopic sites are hypersensitive to wide range of mechanical, thermal and chemical stimuli. Gentle mechanical pressure or brushing may evoke ongoing firing in the injured nerve. When the spot with ectopic activity develop close to tendons or joints, movements and weight bearing may trigger an ongoing pain accompanying various muscoskeletal disorders. Cold allodynia, a common symptom in neuropathy, is related to increased ectopic discharges in unmyelinated $C$ fibers after cold stimulation. Electrophysiological and immunohistochemical studies demonstrated that it could be caused by an altered expression of thermoresponsive vanilloid receptors (Caterina et al., 1997). Chemical stimuli that depolarize sensory neurons may also excite ectopic discharges. Inflammatory and regeneration processes following nerve injury are mediated by cytokines, peptides, neurotrophins and all of these substances have been shown to contribute to development of ectopic discharges. Moreover, local metabolic changes at the site of injury such as tissue ischemia and elevated blood glucose also contribute to the generation of ectopic discharges (Devor et al., 1992; Levy et al., 2000; Noda et al., 1997; Rivera et al., 2000).

The electrophysiological recordings from DRG cells have shown that afterdischarges are present in a form of oscillation, when the burst of responses is followed by hyperpolarization. During this period the activity is suppressed and can not be elicited by another stimulation. The hyperpolarization may be caused by the activation of potassium channels (Amir \& Devor, 1997). The clinical manifestation of this phenomenon is probably the refractory period during paroxysms in trigeminal neuralgia or pain relief by transcutaneous electrical nerve stimulation (Rappaport \& Devor, 1994).

\subsubsection{Peripheral sensitization}

\subsubsection{Sodium channels}

The ability of the injured nerve to generate discharges at various sites may arise from changed expression and trafficking of voltage dependent sodium channels. Nine types of voltage-gated sodium channels have been recognized so far in mammals. They are present throughout the nervous system with the most abundant expression in DRG neurons. They 
are expressed differently during the development when for example NaV1.3 is present only during embryonic stages. Several studies suggest that the ectopic discharges are evoked by an altered expression and distribution of sodium channels. Experimental axotomy in adult animals reduces the level of RNA of NaV1.6, NaV1.7, NaV1.8 and NaV1.9 but upregulates Nav1.3 which is normally not expressed by adult DRGs. Based on the whole-cell patchclamp recordings it is suggested that NaV1.3 may be a key player in neuropathic pain and the neurons expressing this channel may exhibit reduced threshold or a high firing frequency (Dib-Hajj et al., 2009; Dib-Hajj et al., 2007). There are also changes in the redistribution of sodium channels, particularly of NaV1.8, increased immunoreactivity of which was observed at the site of nerve injury. This translocation may contribute to the generation of ectopic discharges (Black et al., 2008; Wood et al., 2004). Recent clinical data demonstrated the link between mutation of human Nav1.7 gene and serious neuropathic disorders, like insensitivity to pain or erythermalgia (Dib-Hajj et al., 2007; Drenth \& Waxman, 2007).

\subsubsection{Transient receptor potential channels}

Transient receptor potential (TRP) channels is a group of cation channels involved in sensory signaling that undergo changes after nerve injury and during inflammation. The most profound changes have been observed in the expression of capsaicin-activated channel TRPV1 after nerve injury. Sciatic nerve section or spinal nerve ligation cause reduced expression of TRPV1 in all damaged DRG neurons while its increase has been observed in the spared undamaged DRG neurons (Baron, 2000; Caterina, 2007, 2008). The involvement of TRPV1 in the development of heat hyperalgesia was demonstrated in experiments where TRPV1 knockout mice did not develop heat hyperalgesia after inflammation. On the other hand, no changes in the level of heat hyperalgesia were observed in knockout mice compared to wild types after nerve injury. These observations point to different molecular mechanisms of heat hyperalgesia during inflammatory and neuropathic pain. The antinociceptive effect of TRPV1 antagonist further supports the idea of crucial role of TRPV1 in the development of neuropathic pain (Baron, 2000; Hudson et al., 2001; Staaf et al., 2009).

\subsubsection{Cytokines}

Among inflammatory mediators that could contribute to the peripheral sensitization, cytokines IL-1 $\beta$ and TNF $\alpha$ have drawn the most attention. The increased expression of both in the DRGs is closely correlated with the reduced mechanical and thermal withdrawal threshold in animals (Schafers et al., 2003; Sorkin \& Doom, 2000). Clinical studies showed that patients with mechanical allodynia have higher levels of serum soluble TNF $\alpha$ receptor. Injection of TNF $\alpha$ or IL-1 $\beta$ receptor antagonists reduced pain-related behavior in experimental animals (Cunha et al., 2000; Sommer \& Kress, 2004).

\subsection{Central changes in neuropathic pain}

The resistance of neuropathic pain to pharmacotherapy suggests that the changes in the pain processing take place also in the central nervous system. In fact, electrophysiological studies showed an increased activity of dorsal horn neurons after peripheral nerve injury (Chapman et al., 1998; Laird \& Bennett, 1993; Palecek et al., 1992). However, no correlation was found between responses of the dorsal horn neurons to heat stimuli and the presence of heat hyperalgesia (Laird \& Bennett, 1993; Palecek et al., 1992). Also the threshold of dorsal horn 
neurons to mechanical stimulation was unchanged after peripheral nerve injury. On the other hand, innocuous stimuli evoked activity in the majority of wide dynamic range neurons and the afterdischarges were more prominent in nerve injured animals (Palecek et al., 1992). The underlying mechanisms for increased activity of dorsal horn neurons after peripheral nerve injury are related to the enhanced release of excitatory amino acids and the attenuation of inhibitory signaling.

\subsubsection{Disinhibition}

The sensory input into the spinal cord is under regulation of inhibitory circuitry maintained by sensory afferents, spinal interneurons and descending inhibition. This regulatory circuitry is disrupted after peripheral nerve injury that leads to misinterpretation of peripheral inputs that could underlie chronic pain development. The main inhibitory neurotransmitters in central nervous system are $\gamma$-aminobutyric acid (GABA) and glycin. The importance of GABA signaling for normal pain processing has been shown in experiments where the blockade of spinal GABAergic neurotransmission by intrathecal antagonists produced hypersensitivity to innocuous tactile stimuli (Gwak et al., 2006; Hao et al., 1994; Malan et al., 2002) and where transgenic mice lacking specific subunits of GABA receptors developed hyperalgesia and allodynia (Schuler et al., 2001; Ugarte et al., 2000). The hyperexcitability of dorsal horn neurons in neuropathic pain has been explained by a disruption of inhibitory tone in the spinal cord. In fact, a reduction of GABA and GABAsynthesizing enzyme GAD has been reported after spinal cord injury and peripheral nerve injury. Also the electrophysiological recordings showed reduced spinal inhibitory tone in the injured animals (Castro-Lopes et al., 1993; Eaton et al., 1998; Gwak et al., 2006; Ibuki et al., 1997; Moore et al., 2002). There still a debate about what is the direct cause of reduced GABA production in the dorsal horn. Histological examinations showed a presence of apoptotic cells in the dorsal horn after constriction injury. It was suggested that they are GABAergic inhibitory interneurons; however, detailed stereological investigation doubted this possibility. The study also showed there is no significant loss of GABAergic or glycinergic neurons in animals with neuropathic pain and that the proportion of GABA immunoreactive neurons was similar to control animals without nerve injury (Polgar et al., 2004; Polgar et al., 2003). However, although dysfunction of spinal inhibition seems to be a major factor in persistent pain syndromes, pharmacological targeting of the GABAergic system has not shown satisfactory outcomes. This is in part likely due to the widespread distribution and actions of GABA throughout the CNS.

\subsubsection{Enhanced release of excitatory neurotransmitters}

There are ample of evidences showing that an activation of glutamate NMDA receptors is involved in the development of neuropathic pain. Recordings from spinal slide preparations of animals with peripheral nerve injury showed enhanced NMDA receptor current, suggesting increased release of glutamate after stimulation (Isaev et al., 2000). The amount of glutamate released from primary afferent fibers into a dorsal horn is controlled by glutamate transporters. Their downregulation after nerve injury contribute to the excess of glutamate in the spinal cord, overactivation of glutamate receptors and hyperexcitability of neurons. Although initial response after nerve injury presents upregulation of glutamate transporters, their expression is reduced later on (Sung et al., 2003). 
The upregulation of dynorphin in the spinal cord after nerve injury has been reported in rats and mice (Gardell et al., 2004; Malan et al., 2000). A strain of mouse that does not develop the signs of neuropathic pain does not show increased level of dynorphin, therefore this protein is a suitable marker associated with nerve injury-induced pain (Gardell et al., 2004). Dynorphin may increase a release of excitatory neurotransmitters from primary afferent fibers as suggested from studies showing that release of calcitonin gene-related peptide, substance $\mathrm{P}$ and excitatory amino acids into dorsal horn is potentiated by dynorphin (Arcaya et al., 1999; Gardell et al., 2003; Koetzner et al., 2004). Also, the pharmacological inhibition of dynorphin abolished the development of mechanical and thermal hypersensitivity in rats and mice after nerve injury; genetic knockout of dynorphin led to only transient hypersensitivity after nerve injury (Gardell et al., 2004). Those studies point to the important role of spinal dynorphin in the persistent pain.

\subsubsection{Reorganization}

Several studies suggested that the nerve injury cause an anatomical reorganization in the spinal dorsal horn allowing the signal from non-nociceptive $A \beta$ fibers to reach and activate nociceptive neurons (Woolf et al., 1992). This idea was based on the observation of positive labeling of superficial dorsal horn laminae with retrograde tracer choleratoxin B (CTB) after nerve injury. This tracer, when injected into peripheral nerve, is uptaken by myelinated neurons expressing GM1 receptor and transported into the spinal cord. CTB labeling in the spinal cord thus identify termination of myelinated fibers. In the normal animals, labeling is found in the deeper dorsal horn laminae. Its presence in the superficial area in the vicinity of nociceptive neurons was explained by sprouting of $A \beta$ fibers from deeper laminae. The nonnociceptive input signaled by $\mathrm{A} \beta$ fibers may thus excite nociceptive neurons and underlie development of mechanical allodynia. However, subsequent studies showed that there is a phenotypic switch in DRG neurons after axotomy as the expression of GM1 receptors was found also on the unmyelinated nociceptive DRG neurons. Therefore, CTB is transported by both myelinated and unmyelinated afferents which explains its appearance in upper dorsal horn laminae, termination of unmyelinated fibers (Bao et al., 2002; Shehab et al., 2003). Although the structural reorganization does not seems to be a case for abnormal A $\beta$ signal processing, electrophysiological experiments showed the increased A $\beta$ input into the dorsal horn.

\subsubsection{Ascending projections-the role of $A \beta$ fibers}

The role of $\mathrm{A} \beta$ fibers in development of tactile allodynia is further supported by evidences showing that injection of sodium channel blocker lidocain into the supraspinal termination of $\mathrm{Ab}$ fibers- nucleus gracilis - block tactile allodynia. An interesting finding in this study was that thermal allodynia was not changed by this treatment (Ossipov et al., 2002; Sun et al., 2001). The expression of neuropeptide $Y$ in DRG neurons after peripheral or spinal nerve injury seems to be related to the activity of $A \beta$ fibers. This protein is not present in DRGs during physiological conditions. After nerve injury its expression is found in DRGs and spinal cord in the area of termination of $A \beta$ fibers (Wakisaka et al., 1991). Neuropeptide $Y$ is also upregulated in the ipsilateral nucleus gracilis after nerve injury (Ossipov et al., 2002). It has been shown that its presence originates from the DRG since neither dorsal rhizotomy 
nor lesion of the dorsal column blocked its appearance in nucleus gracilis. The significance of this supraspinal center for the development of pain was demonstrated in experiments where injection of neuropeptide $\mathrm{Y}$ into nucleus gracilis evoked tactile allodynia. Interestingly, thermal sensitivity was not changed. The findings of these studies indicate that the tactile hypersensitivity is mediated by $A \beta$ input through upregulation of neuropeptide $\mathrm{Y}$ in the DRGs and that the development of tactile hypersensitivity can be modulated from supraspinal areas. Also the modulation of tactile hypersensitivity without affecting thermal sensitivity points out to a different processing of mechanical and thermal nociceptive input.

\subsubsection{Descending modulation}

The spinal processing of nociceptive information is influenced by a descending input that could facilitate or inhibit propagation of the nociceptive signal. The rostral ventromedial medulla (RVM) and periaqueductal gray are the most important sources of the descending control. The electrical stimulation of RVM may elicit both the facilitation or inhibition of nociceptive reflexes and can enhance or inhibit responses of WDR neurons to noxious stimuli (Walker et al., 1999). The facilitatory input from these structures is believed to be critical for the maintenance of neuropathic pain. Spinal transection or hemisection has been shown to abolish development of neuropathic pain signs after peripheral nerve injury (Kauppila et al., 1998) and the lesion of the major pathways connecting RMV to spinal cord, dorsolateral funiculus, also abolished development of neuropathic pain (Burgess et al., 2002). Electrophysiological experiments demonstrated that specific population of RVM cells expressing $\mu$-opioid receptor are directly related to the descending facilitatory input (Heinricher \& Neubert, 2004). The selective ablation of these cells prevented the development of neuropathic pain (Burgess et al., 2002; Porreca et al., 2001).

\subsubsection{The integration of ascending and descending modulation}

The integration of ascending and descending modulation of nociception in the spinal cord was shown in a series of experiments targeting dorsal horn projection neurons. Using ribosome inhibitor protein saporin conjugated with substance $\mathrm{P}$, a specific population of dorsal horn neurons expressing substance P receptor NK1 was eliminated (Nichols et al., 1999; Suzuki et al., 2002). This procedure led to a reduction of tactile and thermal hypersensitivity in rats after peripheral nerve injury or inflammation, suggesting the essential role of those neurons in the development of neuropathic pain. Further experiment revealed that the ablation of NK1 receptor neurons reduced hyperexcitability of wide dynamic range neurons in deeper dorsal horn laminae to mechanical and thermal stimulation (Suzuki et al., 2002). Since the wide dynamic range neurons receive the facilitatory input from RVM by the action of serotonin, a relationship between NK1 neurons and serotonergic pathway was studied. Using serotonin receptor antagonist onadsetron, an effect similar to SP-saporin treatment on wide dynamic range neurons responses was observed (Suzuki et al., 2002). These results demonstrate that the peripheral nerve injury causes an activation of descending facilitatory pathway by signals from ascending fibers arising (at least partially) from NK1 neurons in dorsal horn. The integration of ascending and descending nociceptive signaling contribute to neuropathic pain. 


\section{Animal models of neuropathic pain}

Animal models of acute pain where responses to various mechanical, thermal or electrical stimulations are evaluated provide a good source of our knowledge about basic mechanisms of pain. These models are widely use for the development of analgesic drugs as they provide a reliable outcome comparable to clinical states. However, chronic pain following peripheral or central nerve injury present more difficult task as the drugs successfully used in an acute pain are usually inefficient for neuropathic pain. Our recent knowledge on the mechanisms of neuropathic pain is based on animal models partially mimic some of the clinically observed symptoms of neuropathic pain. The most used models in neuropathic pain research involve injury of the sciatic nerve and specific forms of spinal cord injury. The advantage of sciatic nerve in pain research is based on its anatomical location allowing easy access without extensive surgery and the fact that its branches innervate hind limbs accessible for sensory testing.

\subsection{Sciatic nerve axotomy}

One of the first chronic pain model based on the injury of the sciatic nerve is frank transection of the sciatic nerve (Wall et at., 1979 as cited in (McMahon \& Koltzenburg, 2005)). The painful sensations developed in the denervated area illustrate the paradox of neuropathic pain and mimic clinical state of phantom limb pain. The procedure consists of $5 \mathrm{~mm}$ section of sciatic and saphenous nerve. The complete anesthesia in the affected area is confirmed by the absence of flexion reflex after strong pinch. The various degree of autotomy behavior develops within 5 weeks post injury. The model was further characterized by variations of nerve injuries, when either saphenous or sciatic nerve was transected alone or at different time points and the degree of autotomy behavior was evaluated. The variations in behavioral outcome between different strains of rats and mice were also studied. These experiments showed that sciatic nerve injury alone is sufficient to evoke autotomy behavior and that degree of autotomy varies considerably between different strains of rats and mice. This model showed to be a useful tool to predict clinical efficacy of drugs to relieve phantom limb pain. Drugs such as sodium channel blockers, tricyclic antidepressant and anticonvulsant, which successfully reduced autotomy, also reduced phantom limb pain in patients (Chabal et al., 1989). It also provides a good tool to study electrophysiological changes after nerve transaction, formation of neuroma and development of ectopic discharges. However, since the limb is denervated, one cannot assess pain related behavior, as the animal lack proper motoric function in the affected paw. Therefore there is a controversy about how much this model and autotomy behavior is related to possible pain sensation. Another arguments point to strain variability of autotomy and provide evidences, that such behavior may be modulated by environment. To address these problems, other models of neuropathic pain were developed based on the various degree of sciatic nerve injury.

\subsection{Partial ligation}

Ligation of $1 / 3$ to $1 / 2$ of the sciatic nerve is used to mimic causalgia symptoms after nerve trauma (Seltzer et al., 1990; Shir \& Seltzer, 1990). Rats display no autotomy and develop the signs of spontaneous pain, tactile, mechanical and thermal hyperesthesia. Pain-related behavior is sympathetically maintained as it is abolished after sympathectomy. The 
disadvantage of the model is variability of the degree of nerve injury between animals, resulting in different ratio of injured versus uninjured fibers and random distribution of their termination in the spinal cord.

\subsection{Chronic constriction injury}

Chronic constriction injury present another model of sciatic nerve injury, where four loose ligatures are placed around the nerve, causing swelling and constriction of nerve at the site of ligation (Bennett \& Xie, 1988). Within 1 day post injury the constriction caused by edema reduces diameter of sciatic nerve up to $75 \%$. Histological examination and electron microscopy showed massive reduction of myelinated $A \alpha$ and $A \beta$ fibers and lesser reduction of A $\delta$ (Munger et al., 1992). Electrophysiological experiments indicate almost $90 \%$ loss of myelinated and 30\% unmyelinated fibers 3 days post injury additional loss within 14 days (Coggeshall et al., 1993) (Kajander \& Bennett, 1992). Due to injury to motor fibers, animals walk with a limb with ventroflexed toes. Injury of the sensory fibers results in the development of neuropathic pain symptoms such as thermal and mechanical hyperesthesia. Animals display guarding behavior, avoiding placing weight on the injured paw. There is also an overgrowing of the claws due to reduced grooming. The pain related behavior usually persists up to 2 months. Hypersensitivity to heat is presented in the reduced paw withdrawal latency to the radiant heat. A light tactile stimulation elicits paw withdrawal and expression of nociceptive marker protein c-Fos in dorsal horn (Catheline et al., 1999). Animals also develop cold allodynia demonstrated by exaggerated reaction to the application of acetone. The pain related behavior observed in this model resemble the clinical state of causalgia. Moreover, overgrowing of claws observed in these animals is suggested to be similar to unwillingness of patients to trim their nails as it painful. Animals also display a signs of spontaneous pain by their abnormal posture, guarding behavior and accidental flinches. Although the development of hypersensitivity was attributed to the loss large myelinated A $\beta$ mechanosensitive fibers (Munger et al., 1992), animals did not display robust pain related behavior 2 months post injury in spite of lingering loss of $A \beta$ fibers. Hypersensitivity is probably mediated by sensitized $A \delta$ and $C$ fibers. The ectopic discharges in myelinated fibers are presented proximal to the injury and those may be responsible for the spontaneous and evoked pain-related behavior observed in this model. The disadvantage of this model is again the various degree of nerve injury. Although the variability is lower that in partial ligation model, it is difficult to provide the same degree of constriction in each animal.

\subsection{Spinal nerve ligation}

The model of spinal nerve ligation overcomes the issues of the previous models where it is not possible to control the amount of injured fibers. The model was developed by Kim\&Chung in 1992 (Kim \& Chung, 1992). In this models only spinal L5 and L6 branches of the sciatic nerve are ligated, so the corresponding DRGs and spinal cord segments reflects changes related to nerve injury. Uninjured L4 branch and its DRG help to identify how the nerve injury influences surrounding uninjured nerves. After injury rats show a mild limp with slightly everted paw. The development of pain-related behavior is observed 1-2 days post injury as tactile and thermal allodynia (Chaplan et al., 1994; Ossipov et al., 1999). Those signs persisted up to 10 weeks. Cold allodynia is less pronounced. Electrophysiological 
studies showed an increased number of neurons responding to light mechanical, thermal or cold stimuli although the threshold of response was similar to control animals (Chapman et al., 1998). The experiment where dorsal rhizotomy was performed on attempt to block signals from an injured and uninjured nerve to reach the spinal cord showed that the spontaneous pain may be mediated through injured fibers while the evoked pain requires input from uninjured fibers (Sheen \& Chung, 1993; Yoon et al., 1996).

\subsection{Spared nerve injury}

In spared nerve injury model peripheral branches of the sciatic nerve are ligated and transected (Decosterd \& Woolf, 2000). Peroneal and common tibial branch are injured while sural branch is left intact. Such injury caused tactile thermal and cold allodynia persisting over 9 weeks. The signs of neuropathic pain are most prominent at the areas of the hind paw innervated by an uninjured sural nerve. The design of this model allows studying changes in uninjured nerve fibers sharing the common nerve trunk with injured ones and compared it with uninjured fibers in saphenous nerve innervating basically the same area like the injured nerve branches.

\subsection{Other models of peripheral nerve injury}

Other models of peripheral nerve inujry include immune or toxin-mediated demyelination that simulates demyelinating neuropathy (Wallace et al., 2003). Vincristine, paclitaxel and cisplatin have been used in animal models to mimic polyneuropathy caused by tumor chemotherapy (Peltier \& Russell, 2002). Streptozocin-induced damage to pancreatic insulinproducing cells in rats provides an experimental model of diabetic neuropathy (Rondon et al., 2010).

\subsection{Spinal cord injury}

Neuropathic pain may also develop as a consequence of spinal cord injury (SCI). Although the loss of function is the primary concern of SCI patient, the presence of pain negatively influences the rehabilitation strategies and reduces the quality of life of SCI patients. The prevalence of SCI pain is about 70-80\% (Ravenscroft et al., 1999). Neuropathic pain after SCI is difficult to treat as there are several locations in the neuraxis this pain may arise from; there may be increased activity of neurons around the site of the injury, in the nerve or in the brain. The SCI-induced neuropathic pain is classified as at- level, or below-level pain with an incidence of about 30-40\% (Siddall et al., 2003). Below-level pain is usually described as severe pain and may develop months or years after initial injury. In the case of at-level pain, the pain probably arises from the spinal cord above the injury site. Spinal local anesthetics blockade above the level of SCI produce temporary pain relief in SCI patient while the same procedure is ineffective in patient with spinal canal obstruction where sensory blockade can not be produce above SCI level (Loubser \& Clearman, 1993). The presence of spinal generator of abnormal neuronal activity underlying SCI neuropathic pain was demonstrated in electrophysiological experiments using animal models of SCI where spontaneous activity of the above- level neurons was found after spinal cord transection (Loeser \& Ward, 1967). Following this initial study, a number of SCI pain models have been developed, based on mechanical injury such as transection (Christensen et al., 1996; Levitt \& 
Heybach, 1981; Vierck \& Light, 1999), contusion (Hulsebosch et al., 2000; Lindsey et al., 2000; Siddall et al., 1995), irradiation (Xu et al., 1992) and excitotoxicity (Yezierski \& Park, 1993). Although the mechanism is different, the presence of SCI pain in these models is evident within couple of days and persists for several weeks to months. The electrophysiological recordings showed an increased background activity of spinal cord neurons, an increased responsiveness to peripheral stimuli and prolonged afterdischarges. The current explanation of such changes is based on the dysfunction of the inhibitory circuitry in the spinal cord, enhanced excitation of neurons through glutamate receptors and changes in the expression of sodium channels (Hains et al., 2003).

The regeneration strategies after SCI may also be related to the development of neuropathic pain. There are evidences that fibers producing excitatory neurotransmitter calcitonin generelated peptide grow from the superficial lamine into deeper areas and that this reorganization is related to pain behavior (Christensen \& Hulsebosch, 1997).

The ongoing pain sensations have been reported in some SCI patients despite of extensive pharmacological and surgical treatments, including removing a part of the spinal cord. Such observations suggest the pain may arise from supraspinal structures. It is not clear which centers in brain may be involved in such pain, although there are some evidences towards electrophysiological and metabolic changes of thalamic neurons (Defrin et al., 2001).

\section{Pharmacotherapy of neuropathic pain}

The effective pharmacological treatment of neuropathic pain should target an underlying mechanism of given pain state. Although there are usually numerous changes in the processing of nociceptive input that cause neuropathic pain, the idea is to target the most dominant mechanisms to achieve a reduction of pain. Based on our current knowledges on the underlying mechanisms of neuropathic pain, treatments are being developed to reduce the release of pronociceptive neurotransmitters by opiates or calcium channel-binding drugs, to regulate glutamate signaling by inhibiting postsynaptic NMDA receptors, to potentiate inhibitory neurotransmitter by agonist administration, reuptake inhibitors or sodium channel blockers.

Although the conventional analgesics showed to be ineffective in a relieving of NP symptoms, drugs originally developed to restore a balance in the level of neurotransmitter in CNS or to modulate transmembrane potential and excitability of neurons, have been successfully used to reduce some of the neuropathic pain symptoms. However, none of these drugs are able to produce long lasting pain relief. Moreover, their long term use is often negatively influenced by adverse side effects. Therefore there is still a need for better therapies. The currently used pharmacotherapy includes tricyclic antidepressants, anticonvulsants and opioids.

One of the first group of drugs used in clinical trials for neuropathic pain were tricyclic antidepressants (Watson et al., 1982). They proved to be temporarily efficacious in various neuropathic pain conditions but with many side effects. Newer classes of antidepressant that alter serotonergic and noradrenergic signaling have better tolerability and widely used in NP treatment (Rowbotham et al., 2004; Sawynok \& Reid, 2001). Sodium channel blockers such as anticonvulsant and local anesthetic drugs reduce the ectopic discharges originating 
at the injury site. The high specificity of these drugs for sodium channels allows using them systematically without serious failure of normal sodium channel functioning necessary for impulse propagation in nervous system, although a potential cardiac toxicity is an obstacle for their wider use in NP treatment. Gabapentin, an anticonvulsant originally developed to interact with GABA receptors and to increase inhibitory tone when GABA signaling is impaired, have an analgesic effect in some form of neuropathic pain. Its action is not mediated via GABA receptors though; it is believed it acts through voltage- gated calcium channels (Taylor et al., 1998). Voltage-gated calcium channels ( $\mathrm{N}$ and $\mathrm{T}$ family) regulate the influx of calcium into the cell upon proper stimulus. Increase in the intracellular calcium in the neuromuscular junctions cause the contraction of muscle and release of neurotransmitters from nerves. Expression of one of the $\mathrm{N}$ type of calcium channel family, $\alpha 1 B$, in the superficial laminae of the dorsal horn after the nerve injury and the correlation with the pain behavior point to their involvement in nociception (Cizkova et al., 2002). Calcium channels are therefore an attractive target for development of novel analgesic drugs (Perret \& Luo, 2009). Opioid therapy proved to be effective in various form of neuropathic pain (Foley, 2003; Zochodne \& Max, 2003). However, as with every drug used in chronic pain treatment, negative side effects such as cognitive impairment, sedation, tolerance and addiction are a limiting factor.

\section{Cell based therapy}

In search for novel approaches for neuropathic pain treatment, cell based therapy has potential to overcome issues of traditional pharmacotherapy. Transplantation, either intraspinal or intrathecal, of cells releasing analgesic substances provide targeted delivery of desired drug and thus reducing adverse side effects due to its widespread action after oral or systemic injection. Also, local delivery of drugs via indwelling catheters is often limited by possible infections, especially in chronic implantations.

As one of the major factors in persistent pain syndromes is reduced GABAergic inhibitory control, delivery of GABA via cell based therapy has been extensively studied. Intraspinal grafting of GABAergic cells derived from fetal mouse striatum or fetal human telencephalon reduced tactile allodynia in L5/6 spinal nerve ligation model (Mukhida et al., 2007). Intrathecal or intraspinal injection of GABAergic cells derived from human teratocarcinoma cell line (hNT) has also showed positive effect in reducing spinal cord injury pain and spasticity in experimental models (Eaton et al., 2007; Marsala et al., 2004). Enhanced delivery of GABA via gene therapy approaches have shown promise in preclinical models, notably the administration of GAD65-expressing rAAV2 to sciatic nerve or DRG (Kim et al., 2009) and peripherally delivered HSV-based vectors engineered to produce either GAD65 or GAD67 in DRG (Hao et al., 2005) can reduce peripheral neuropathic or SCI pain. Previous findings in our laboratory have shown that the transplantation of neural progenitor cells expressing GABA into the dorsal horn of animals with excitotoxic spinal cord injury can reduce symptoms of spontaneous pain, and can reduce spinal hyperexcitability (wind-up) and hyperalgesia in animals with chronic constriction injury (Jergova et al., 2009; Lee et al., 2001). To enhance the efficiency of GABAergic cell therapy, several approaches are investigated. Recent study demonstrated increased yield of GABAergic precursor cells under a low concentration of the fibroblast growth factor in a cell culture. Also, genetic 
modification where specific transcriptional factor was blocked promoted GABAergic and reduced glial differentiation (Furmanski et al., 2009).

\section{Gene therapy}

The most promising approach in alleviating chronic pain may be the use of genetically modified cells releasing combination of molecules with distinct antinociceptive mechanisms. Research in our laboratory is focused on two potential candidates, serine-histogranin, targeting enhanced glutamatergic signaling and conotoxins targeting increased expression of calcium channels.

\subsection{Serine-histogranin}

[Ser1] histogranin (SHG) is synthetic analog of histogranin, peptide produced by adrenal glands, pituitary, brain and other tissues (Lemaire et al., 1993) with inhibitory properties at glutamate NMDA receptors (Shukla et al., 1995). Findings in our laboratory suggest that SHG can produce prolonged inhibition of spinal nociceptive responses to a variety of stimuli, and may interact at unique excitatory amino acid receptive sites in the spinal dorsal horn (Hentall et al., 2007). Intrathecal injection of SHG can block NMDA induced hyperalgesia and allodynia with no apparent adverse motor effects (Siegan \& Sagen, 1995) in contrast to findings with another NMDA antagonists, MK-801 (Hama \& Sagen, 2002; Hama et al., 2003). Recent results showed potentiation of antinociceptive effect of GABAergic transplant by intrathecally injected SHG in the model of peripheral nerve injury (Jergova et al., 2011b).

Previous experience in our laboratory has demonstrated that neuronal progenitor cells readily express transgenes, and thus make an ideal vehicle for delivery of novel analgesic peptides(Gajavelli et al., 2008). An enhanced GABAergic precursor cells transfected by SHG cDNA were recently developed. After intraspinal transplantation they significantly reduced cold allodynia and mechanical hyperalgesia in models of spinal cord injury and peripheral nerve injury-induced pain (Jergova et al., 2011a).

\subsection{Conopeptides}

Conotoxins are neurotoxic peptides isolated from the venom of marine snail Conus with selective ion channel blocking activity. There are 5 different classes of conotoxins based on the channel or receptor they target: $\alpha$-conotoxin inhibit nicotinic acetylcholine receptors, $\delta$ conotoxin target voltage-dependent sodium channels, $\kappa$-conotoxin inhibits potassium channels, $\mu$-conotoxin inhibits voltage-dependent sodium channels in muscles, $\omega$-conotoxin inhibits N-type voltage-dependent calcium channels. The analgesic effect of $\omega$-conotoxin MVIIA is 100 to 1000 times more potent that of morphine and its synthetic version ziconotide is used in clinical treatment of neuropathic pain (Malmberg \& Yaksh, 1995; Olivera, 2006; Wallace et al., 2008). Another group of conopeptides- conantokins, with NMDA antagonist activity is also very interesting in pain research, as enhanced activity of NMDA receptors is hypothesized to contribute to onoing pain (Teichert et al., 2007).

Clinical use of analgesic peptides is limited by poor CNS penetration and thus need to be delivered via intrathecal pumps. However, conopeptides are ideal candidates for 
recombinant expression at target sites to spinal cord pain processing centers using cell or molecular based strategies. In our laboratory, the intrathecal administration of N-tpe calcium channel inhibitor $\omega$-conotoxin MVIIA produced marked reduction of neuropathic pain symptoms in animals with compression SCI, a particularly difficult clinical target (Hama \& Sagen, 2009). Another conopeptide with NMDA antagonist activity, ConG, was found to be very efficient in reducing allodynia in SCI model. When used in combination with conopeptide MVIIA, more robust analgesic effect was observed. Isobolographic analysis showed synergistic effect of these conopeptides, an important finding considering possible side effects in prolonged administration of drugs. Synergism allows using lower concentration of drugs to achieve analgesic effect comparable to separate administration of those drugs at higher concentration. In addition, combination of conopeptide with GABAergic cell grafts may be particularly potent, as combined intrathecal ziconotide and baclofen have been reported to improve neuropathic pain scores in a recent case report (Saulino et al., 2009).

\section{Conclusion}

The restoration of inhibitory function in the spinal dorsal horn by neural transplantation is a promising strategy for alleviating persistent pain following injury to the nervous system. The recent availability of stem cells that can be directed towards desired neuronal phenotypes and also can be genetically manipulated to produce additional potent therapeutic agents offers the opportunity for targeted pain management and improved outcomes of chronic pain therapies.

\section{References}

Ali, Z.; Ringkamp, M.; Hartke, T.V.; Chien, H.F.; Flavahan, N.A.; Campbell, J.N. \& Meyer, R.A. (1999). Uninjured C-fiber nociceptors develop spontaneous activity and alphaadrenergic sensitivity following L6 spinal nerve ligation in monkey. J Neurophysiol, Vol.81, No.2, 455-466.

Amir, R. \& Devor, M. (1997). Spike-evoked suppression and burst patterning in dorsal root ganglion neurons of the rat. J Physiol, Vol.501 ( Pt 1), 183-196.

Arcaya, J.L.; Cano, G.; Gomez, G.; Maixner, W. \& Suarez-Roca, H. (1999). Dynorphin A increases substance $\mathrm{P}$ release from trigeminal primary afferent C-fibers. Eur J Pharmacol, Vol.366, No.1, 27-34.

Bao, L.; Wang, H.F.; Cai, H.J.; Tong, Y.G.; Jin, S.X.; Lu, Y.J.; Grant, G.; Hokfelt, T. \& Zhang, X. (2002). Peripheral axotomy induces only very limited sprouting of coarse myelinated afferents into inner lamina II of rat spinal cord. Eur J Neurosci, Vol.16, No.2, 175-185.

Baron, R. (2000). Capsaicin and nociception: from basic mechanisms to novel drugs. Lancet, Vol.356, No.9232, 785-787.

Bennett, G.J. \& Xie, Y.K. (1988). A peripheral mononeuropathy in rat that produces disorders of pain sensation like those seen in man. Pain, Vol.33, No.1, 87-107.

Black, J.A.; Nikolajsen, L.; Kroner, K.; Jensen, T.S. \& Waxman, S.G. (2008). Multiple sodium channel isoforms and mitogen-activated protein kinases are present in painful human neuromas. Ann Neurol, Vol.64, No.6, 644-653. 
Burgess, S.E.; Gardell, L.R.; Ossipov, M.H.; Malan, T.P., Jr.; Vanderah, T.W.; Lai, J. \& Porreca, F. (2002). Time-dependent descending facilitation from the rostral ventromedial medulla maintains, but does not initiate, neuropathic pain. J Neurosci, Vol.22, No.12, 5129-5136.

Campero, M.; Serra, J.; Marchettini, P. \& Ochoa, J.L. (1998). Ectopic impulse generation and autoexcitation in single myelinated afferent fibers in patients with peripheral neuropathy and positive sensory symptoms. Muscle Nerve, Vol.21, No.12, 16611667.

Castro-Lopes, J.M.; Tavares, I. \& Coimbra, A. (1993). GABA decreases in the spinal cord dorsal horn after peripheral neurectomy. Brain Res, Vol.620, No.2, 287-291.

Caterina, M.J. (2007). Transient receptor potential ion channels as participants in thermosensation and thermoregulation. Am J Physiol Regul Integr Comp Physiol, Vol.292, No.1, R64-76.

Caterina, M.J. (2008). On the thermoregulatory perils of TRPV1 antagonism. Pain, Vol.136, No.1-2, 3-4.

Caterina, M.J.; Schumacher, M.A.; Tominaga, M.; Rosen, T.A.; Levine, J.D. \& Julius, D. (1997). The capsaicin receptor: a heat-activated ion channel in the pain pathway. Nature, Vol.389, No.6653, 816-824.

Catheline, G.; Le Guen, S.; Honore, P. \& Besson, J.M. (1999). Are there long-term changes in the basal or evoked Fos expression in the dorsal horn of the spinal cord of the mononeuropathic rat? Pain, Vol.80, No.1-2, 347-357.

Chabal, C.; Jacobson, L.; Russell, L.C. \& Burchiel, K.J. (1989). Pain responses to perineuromal injection of normal saline, gallamine, and lidocaine in humans. Pain, Vol.36, No.3, 321-325.

Chaplan, S.R.; Bach, F.W.; Pogrel, J.W.; Chung, J.M. \& Yaksh, T.L. (1994). Quantitative assessment of tactile allodynia in the rat paw. J Neurosci Methods, Vol.53, No.1, 5563.

Chapman, V.; Suzuki, R. \& Dickenson, A.H. (1998). Electrophysiological characterization of spinal neuronal response properties in anaesthetized rats after ligation of spinal nerves L5-L6. J Physiol, Vol.507 ( Pt 3), 881-894.

Christensen, M.D.; Everhart, A.W.; Pickelman, J.T. \& Hulsebosch, C.E. (1996). Mechanical and thermal allodynia in chronic central pain following spinal cord injury. Pain, Vol.68, No.1, 97-107.

Christensen, M.D. \& Hulsebosch, C.E. (1997). Chronic central pain after spinal cord injury. J Neurotrauma, Vol.14, No.8, 517-537.

Cizkova, D.; Marsala, J.; Lukacova, N.; Marsala, M.; Jergova, S.; Orendacova, J. \& Yaksh, T.L. (2002). Localization of N-type Ca2+ channels in the rat spinal cord following chronic constrictive nerve injury. Exp Brain Res, Vol.147, No.4, 456-463.

Coggeshall, R.E.; Dougherty, P.M.; Pover, C.M. \& Carlton, S.M. (1993). Is large myelinated fiber loss associated with hyperalgesia in a model of experimental peripheral neuropathy in the rat? Pain, Vol.52, No.2, 233-242.

Cunha, J.M.; Cunha, F.Q.; Poole, S. \& Ferreira, S.H. (2000). Cytokine-mediated inflammatory hyperalgesia limited by interleukin-1 receptor antagonist. Br J Pharmacol, Vol.130, No.6, 1418-1424. 
Daousi, C.; MacFarlane, I.A.; Woodward, A.; Nurmikko, T.J.; Bundred, P.E. \& Benbow, S.J. (2004). Chronic painful peripheral neuropathy in an urban community: a controlled comparison of people with and without diabetes. Diabet Med, Vol.21, No.9, 976-982.

Decosterd, I. \& Woolf, C.J. (2000). Spared nerve injury: an animal model of persistent peripheral neuropathic pain. Pain, Vol.87, No.2, 149-158.

Defrin, R.; Ohry, A.; Blumen, N. \& Urca, G. (2001). Characterization of chronic pain and somatosensory function in spinal cord injury subjects. Pain, Vol.89, No.2-3, 253-263.

Devor, M.; White, D.M.; Goetzl, E.J. \& Levine, J.D. (1992). Eicosanoids, but not tachykinins, excite C-fiber endings in rat sciatic nerve-end neuromas. Neuroreport, Vol.3, No.1, 21-24.

Dib-Hajj, S.D.; Binshtok, A.M.; Cummins, T.R.; Jarvis, M.F.; Samad, T. \& Zimmermann, K. (2009). Voltage-gated sodium channels in pain states: role in pathophysiology and targets for treatment. Brain Res Rev, Vol.60, No.1, 65-83.

Dib-Hajj, S.D.; Cummins, T.R.; Black, J.A. \& Waxman, S.G. (2007). From genes to pain: Na v 1.7 and human pain disorders. Trends Neurosci, Vol.30, No.11, 555-563.

Dobretsov, M.; Hastings, S.L.; Stimers, J.R. \& Zhang, J.M. (2001). Mechanical hyperalgesia in rats with chronic perfusion of lumbar dorsal root ganglion with hyperglycemic solution. J Neurosci Methods, Vol.110, No.1-2, 9-15.

Drenth, J.P. \& Waxman, S.G. (2007). Mutations in sodium-channel gene SCN9A cause a spectrum of human genetic pain disorders. J Clin Invest, Vol.117, No.12, 3603-3609.

Eaton, M.J.; Plunkett, J.A.; Karmally, S.; Martinez, M.A. \& Montanez, K. (1998). Changes in GAD- and GABA- immunoreactivity in the spinal dorsal horn after peripheral nerve injury and promotion of recovery by lumbar transplant of immortalized serotonergic precursors. J Chem Neuroanat, Vol.16, No.1, 57-72.

Eaton, M.J.; Wolfe, S.Q.; Martinez, M.; Hernandez, M.; Furst, C.; Huang, J.; Frydel, B.R. \& Gomez-Marin, O. (2007). Subarachnoid transplant of a human neuronal cell line attenuates chronic allodynia and hyperalgesia after excitotoxic spinal cord injury in the rat. J Pain, Vol.8, No.1, 33-50.

Foley, K.M. (2003). Opioids and chronic neuropathic pain. N Engl J Med, Vol.348, No.13, 1279-1281.

Furmanski, O.; Gajavelli, S.; Lee, J.W.; Collado, M.E.; Jergova, S. \& Sagen, J. (2009). Combined extrinsic and intrinsic manipulations exert complementary neuronal enrichment in embryonic rat neural precursor cultures: an in vitro and in vivo analysis. J Comp Neurol, Vol.515, No.1, 56-71.

Gajavelli, S.; Castellanos, D.A.; Furmanski, O.; Schiller, P.C. \& Sagen, J. (2008). Sustained analgesic peptide secretion and cell labeling using a novel genetic modification. Cell Transplant, Vol.17, No.4, 445-455.

Gardell, L.R.; Ibrahim, M.; Wang, R.; Wang, Z.; Ossipov, M.H.; Malan, T.P., Jr.; Porreca, F. \& Lai, J. (2004). Mouse strains that lack spinal dynorphin upregulation after peripheral nerve injury do not develop neuropathic pain. Neuroscience, Vol.123, No.1, 43-52.

Gardell, L.R.; Vanderah, T.W.; Gardell, S.E.; Wang, R.; Ossipov, M.H.; Lai, J. \& Porreca, F. (2003). Enhanced evoked excitatory transmitter release in experimental neuropathy requires descending facilitation. J Neurosci, Vol.23, No.23, 8370-8379. 
Guo, A.; Vulchanova, L.; Wang, J.; Li, X. \& Elde, R. (1999). Immunocytochemical localization of the vanilloid receptor 1 (VR1): relationship to neuropeptides, the P2X3 purinoceptor and IB4 binding sites. Eur J Neurosci, Vol.11, No.3, 946-958.

Gwak, Y.S.; Tan, H.Y.; Nam, T.S.; Paik, K.S.; Hulsebosch, C.E. \& Leem, J.W. (2006). Activation of spinal GABA receptors attenuates chronic central neuropathic pain after spinal cord injury. J Neurotrauma, Vol.23, No.7, 1111-1124.

Hains, B.C.; Klein, J.P.; Saab, C.Y.; Craner, M.J.; Black, J.A. \& Waxman, S.G. (2003). Upregulation of sodium channel Nav1.3 and functional involvement in neuronal hyperexcitability associated with central neuropathic pain after spinal cord injury. $J$ Neurosci, Vol.23, No.26, 8881-8892.

Hama, A. \& Sagen, J. (2002). Selective antihyperalgesic effect of [Ser1] histogranin on complete Freund's adjuvant-induced hyperalgesia in rats. Pain, Vol.95, No.1-2, 1521.

Hama, A. \& Sagen, J. (2009). Antinociceptive effects of the marine snail peptides conantokin$\mathrm{G}$ and conotoxin MVIIA alone and in combination in rat models of pain. Neuropharmacology, Vol.56, No.2, 556-563.

Hama, A.; Woon Lee, J. \& Sagen, J. (2003). Differential efficacy of intrathecal NMDA receptor antagonists on inflammatory mechanical and thermal hyperalgesia in rats. Eur J Pharmacol, Vol.459, No.1, 49-58.

Hao, J.X.; Xu, X.J. \& Wiesenfeld-Hallin, Z. (1994). Intrathecal gamma-aminobutyric acidB (GABAB) receptor antagonist CGP 35348 induces hypersensitivity to mechanical stimuli in the rat. Neurosci Lett, Vol.182, No.2, 299-302.

Hao, S.; Mata, M.; Wolfe, D.; Huang, S.; Glorioso, J.C. \& Fink, D.J. (2005). Gene transfer of glutamic acid decarboxylase reduces neuropathic pain. Ann Neurol, Vol.57, No.6, 914-918.

Heinricher, M.M. \& Neubert, M.J. (2004). Neural basis for the hyperalgesic action of cholecystokinin in the rostral ventromedial medulla. J Neurophysiol, Vol.92, No.4, 1982-1989.

Hentall, I.D.; Hargraves, W.A. \& Sagen, J. (2007). Inhibition by the chromaffin cell-derived peptide serine-histogranin in the rat's dorsal horn. Neurosci Lett, Vol.419, No.1, 8892.

Hudson, L.J.; Bevan, S.; Wotherspoon, G.; Gentry, C.; Fox, A. \& Winter, J. (2001). VR1 protein expression increases in undamaged DRG neurons after partial nerve injury. Eur J Neurosci, Vol.13, No.11, 2105-2114.

Hulsebosch, C.E.; Xu, G.Y.; Perez-Polo, J.R.; Westlund, K.N.; Taylor, C.P. \& McAdoo, D.J. (2000). Rodent model of chronic central pain after spinal cord contusion injury and effects of gabapentin. J Neurotrauma, Vol.17, No.12, 1205-1217.

Ibuki, T.; Hama, A.T.; Wang, X.T.; Pappas, G.D. \& Sagen, J. (1997). Loss of GABAimmunoreactivity in the spinal dorsal horn of rats with peripheral nerve injury and promotion of recovery by adrenal medullary grafts. Neuroscience, Vol.76, No.3, 845858.

Isaev, D.; Gerber, G.; Park, S.K.; Chung, J.M. \& Randik, M. (2000). Facilitation of NMDAinduced currents and $\mathrm{Ca} 2+$ transients in the rat substantia gelatinosa neurons after ligation of L5-L6 spinal nerves. Neuroreport, Vol.11, No.18, 4055-4061.

Jergova, S.; Collante, D.; Bartley, S.; Rodriguez, C.; Pamphile, G.; Gajavelli, S. \& Sagen, J. (2011a). Intraspinal transplantation of recombinant neuroprogenitor cells in a 
spinal cord injury model of central neuropathic pain, The 29th Annual National Neurotrauma Society Symposium Fort Lauderdale, Florida

Jergova, S.; Furmanski, O.; Collado, M.; Varghese, M.; Gajavelli, S.; Manoah, L.; Hentall, I. \& Sagen, J. (2009). Behavioral and neurophysiological effects of GABAergic neuronal precursor cell transplantation in a rat model of chronic neuropathic pain, Society of Neuroscience Abstracts, Chicago, Illinois

Jergova, S.; Varghese, M.S.; Collante, D.; Gajavelli, S. \& Sagen, J. (2011b). Antinociceptive effect of recombinant neuroprogenitor intraspinal transplants in models of peripheral and central neuropathic pain, 30th Annual Sientific Meeting of the American Pain Society, Austin, Texas

Kajander, K.C. \& Bennett, G.J. (1992). Onset of a painful peripheral neuropathy in rat: a partial and differential deafferentation and spontaneous discharge in A beta and A delta primary afferent neurons. J Neurophysiol, Vol.68, No.3, 734-744.

Kauppila, T.; Kontinen, V.K. \& Pertovaara, A. (1998). Influence of spinalization on spinal withdrawal reflex responses varies depending on the submodality of the test stimulus and the experimental pathophysiological condition in the rat. Brain Res, Vol.797, No.2, 234-242.

Kim, J.; Kim, S.J.; Lee, H. \& Chang, J.W. (2009). Effective neuropathic pain relief through sciatic nerve administration of GAD65-expressing rAAV2. Biochem Biophys Res Commun, Vol.388, No.1, 73-78.

Kim, S.H. \& Chung, J.M. (1992). An experimental model for peripheral neuropathy produced by segmental spinal nerve ligation in the rat. Pain, Vol.50, No.3, 355-363.

Klede, M.; Handwerker, H.O. \& Schmelz, M. (2003). Central origin of secondary mechanical hyperalgesia. J Neurophysiol, Vol.90, No.1, 353-359.

Koetzner, L.; Hua, X.Y.; Lai, J.; Porreca, F. \& Yaksh, T. (2004). Nonopioid actions of intrathecal dynorphin evoke spinal excitatory amino acid and prostaglandin E2 release mediated by cyclooxygenase-1 and -2. J Neurosci, Vol.24, No.6, 1451-1458.

Koppert, W.; Dern, S.K.; Sittl, R.; Albrecht, S.; Schuttler, J. \& Schmelz, M. (2001). A new model of electrically evoked pain and hyperalgesia in human skin: the effects of intravenous alfentanil, S(+)-ketamine, and lidocaine. Anesthesiology, Vol.95, No.2, 395-402.

Kress, M. \& Fickenscher, H. (2001). Infection by human varicella-zoster virus confers norepinephrine sensitivity to sensory neurons from rat dorsal root ganglia. FASEB J, Vol.15, No.6, 1037-1043.

Laird, J.M. \& Bennett, G.J. (1993). An electrophysiological study of dorsal horn neurons in the spinal cord of rats with an experimental peripheral neuropathy. J Neurophysiol, Vol.69, No.6, 2072-2085.

Lee, J.W.; Yezierski, R.P. \& Sagen, J. (2001). Transplantation of embryonic precursor cells into excitotoxically lesioned adult spinal cord: In vivo survival and differentiation in quisqualic acid-treated spinal cord. . Soc Neurosci Abs, Vol.27, 369.

Lemaire, P.; Garrett, N.; Kato, K. \& Gurdon, J.B. (1993). Construction of subtracted cDNA libraries enriched for cDNAs for genes expressed in the mesoderm of early Xenopus gastrulae. C R Acad Sci III, Vol.316, No.9, 931-944.

Levitt, M. \& Heybach, J.P. (1981). The deafferentation syndrome in genetically blind rats: a model of the painful phantom limb. Pain, Vol.10, No.1, 67-73. 
Levy, D.; Tal, M.; Hoke, A. \& Zochodne, D.W. (2000). Transient action of the endothelial constitutive nitric oxide synthase (ecNOS) mediates the development of thermal hypersensitivity following peripheral nerve injury. European Journal of Neuroscience, Vol.12, No.7, 2323-2332.

Lindsey, A.E.; LoVerso, R.L.; Tovar, C.A.; Hill, C.E.; Beattie, M.S. \& Bresnahan, J.C. (2000). An analysis of changes in sensory thresholds to mild tactile and cold stimuli after experimental spinal cord injury in the rat. Neurorehabil Neural Repair, Vol.14, No.4, 287-300.

Liu, C.N.; Wall, P.D.; Ben-Dor, E.; Michaelis, M.; Amir, R. \& Devor, M. (2000). Tactile allodynia in the absence of C-fiber activation: altered firing properties of DRG neurons following spinal nerve injury. Pain, Vol.85, No.3, 503-521.

Loeser, J.D. \& Ward, A.A., Jr. (1967). Some effects of deafferentation on neurons of the cat spinal cord. Arch Neurol, Vol.17, No.6, 629-636.

Loubser, P.G. \& Clearman, R.R. (1993). Evaluation of central spinal cord injury pain with diagnostic spinal anesthesia. Anesthesiology, Vol.79, No.2, 376-378.

Malan, T.P.; Mata, H.P. \& Porreca, F. (2002). Spinal GABA(A) and GABA(B) receptor pharmacology in a rat model of neuropathic pain. Anesthesiology, Vol.96, No.5, 1161-1167.

Malan, T.P.; Ossipov, M.H.; Gardell, L.R.; Ibrahim, M.; Bian, D.; Lai, J. \& Porreca, F. (2000). Extraterritorial neuropathic pain correlates with multisegmental elevation of spinal dynorphin in nerve-injured rats. Pain, Vol.86, No.1-2, 185-194.

Malmberg, A.B. \& Yaksh, T.L. (1995). Effect of continuous intrathecal infusion of omegaconopeptides, N-type calcium-channel blockers, on behavior and antinociception in the formalin and hot-plate tests in rats. Pain, Vol.60, No.1, 83-90.

Marsala, M.; Kakinohana, O.; Yaksh, T.L.; Tomori, Z.; Marsala, S. \& Cizkova, D. (2004). Spinal implantation of hNT neurons and neuronal precursors: graft survival and functional effects in rats with ischemic spastic paraplegia. Eur J Neurosci, Vol.20, No.9, 2401-2414.

McMahon, S. \& Koltzenburg, M. (2005). Wall and Melzack's Textbook of Pain. Elsevier.

Michael, G.J. \& Priestley, J.V. (1999). Differential expression of the mRNA for the vanilloid receptor subtype 1 in cells of the adult rat dorsal root and nodose ganglia and its downregulation by axotomy. J Neurosci, Vol.19, No.5, 1844-1854.

Moore, K.A.; Kohno, T.; Karchewski, L.A.; Scholz, J.; Baba, H. \& Woolf, C.J. (2002). Partial peripheral nerve injury promotes a selective loss of GABAergic inhibition in the superficial dorsal horn of the spinal cord. J Neurosci, Vol.22, No.15, 6724-6731.

Mukhida, K.; Mendez, I.; McLeod, M.; Kobayashi, N.; Haughn, C.; Milne, B.; Baghbaderani, B.; Sen, A.; Behie, L.A. \& Hong, M. (2007). Spinal GABAergic Transplants Attenuate Mechanical Allodynia in a Rat Model of Neuropathic Pain. Stem Cells, Vol.25, No.11, 2874-2885.

Munger, B.L.; Bennett, G.J. \& Kajander, K.C. (1992). An experimental painful peripheral neuropathy due to nerve constriction. I. Axonal pathology in the sciatic nerve. Exp Neurol, Vol.118, No.2, 204-214.

Nichols, M.L.; Allen, B.J.; Rogers, S.D.; Ghilardi, J.R.; Honore, P.; Luger, N.M.; Finke, M.P.; Li, J.; Lappi, D.A.; Simone, D.A. \& Mantyh, P.W. (1999). Transmission of chronic nociception by spinal neurons expressing the substance P receptor. Science, Vol.286, No.5444, 1558-1561. 
Noda, K.; Ueda, Y.; Suzuki, K. \& Yoda, K. (1997). Excitatory effects of algesic compounds on neuronal processes in murine dorsal root ganglion cell culture. Brain Res, Vol.751, No.2, 348-351.

Olivera, B.M. (2006). Conus peptides: biodiversity-based discovery and exogenomics. J Biol Chem, Vol.281, No.42, 31173-31177.

Orstavik, K.; Weidner, C.; Schmidt, R.; Schmelz, M.; Hilliges, M.; Jorum, E.; Handwerker, H. \& Torebjork, E. (2003). Pathological C-fibres in patients with a chronic painful condition. Brain, Vol.126, No.Pt 3, 567-578.

Ossipov, M.H.; Bian, D.; Malan, T.P., Jr.; Lai, J. \& Porreca, F. (1999). Lack of involvement of capsaicin-sensitive primary afferents in nerve-ligation injury induced tactile allodynia in rats. Pain, Vol.79, No.2-3, 127-133.

Ossipov, M.H.; Zhang, E.T.; Carvajal, C.; Gardell, L.; Quirion, R.; Dumont, Y.; Lai, J. \& Porreca, F. (2002). Selective mediation of nerve injury-induced tactile hypersensitivity by neuropeptide Y. J Neurosci, Vol.22, No.22, 9858-9867.

Palecek, J.; Dougherty, P.M.; Kim, S.H.; Paleckova, V.; Lekan, H.; Chung, J.M.; Carlton, S.M. \& Willis, W.D. (1992). Responses of spinothalamic tract neurons to mechanical and thermal stimuli in an experimental model of peripheral neuropathy in primates. $J$ Neurophysiol, Vol.68, No.6, 1951-1966.

Peltier, A.C. \& Russell, J.W. (2002). Recent advances in drug-induced neuropathies. Curr Opin Neurol, Vol.15, No.5, 633-638.

Perret, D. \& Luo, Z.D. (2009). Targeting voltage-gated calcium channels for neuropathic pain management. Neurotherapeutics, Vol.6, No.4, 679-692.

Polgar, E.; Gray, S.; Riddell, J.S. \& Todd, A.J. (2004). Lack of evidence for significant neuronal loss in laminae I-III of the spinal dorsal horn of the rat in the chronic constriction injury model. Pain, Vol.111, No.1-2, 144-150.

Polgar, E.; Hughes, D.I.; Riddell, J.S.; Maxwell, D.J.; Puskar, Z. \& Todd, A.J. (2003). Selective loss of spinal GABAergic or glycinergic neurons is not necessary for development of thermal hyperalgesia in the chronic constriction injury model of neuropathic pain. Pain, Vol.104, No.1-2, 229-239.

Porreca, F.; Burgess, S.E.; Gardell, L.R.; Vanderah, T.W.; Malan, T.P., Jr.; Ossipov, M.H.; Lappi, D.A. \& Lai, J. (2001). Inhibition of neuropathic pain by selective ablation of brainstem medullary cells expressing the mu-opioid receptor. J Neurosci, Vol.21, No.14, 5281-5288.

Rappaport, Z.H. \& Devor, M. (1994). Trigeminal neuralgia: the role of self-sustaining discharge in the trigeminal ganglion. Pain, Vol.56, No.2, 127-138.

Ravenscroft, A.; Ahmed, Y.S. \& Burnside, I.G. (1999). Chronic pain after spinal cord injury: a survey of practice in UK spinal injury units. Spinal Cord, Vol.37, No.1, 25-28.

Reeh, P.W.; Bayer, J.; Kocher, L. \& Handwerker, H.O. (1987). Sensitization of nociceptive cutaneous nerve fibers from the rat's tail by noxious mechanical stimulation. Exp Brain Res, Vol.65, No.3, 505-512.

Rivera, L.; Gallar, J.; Pozo, M.A. \& Belmonte, C. (2000). Responses of nerve fibres of the rat saphenous nerve neuroma to mechanical and chemical stimulation: an in vitro study. J Physiol, Vol.527 Pt 2, 305-313.

Rondon, L.J.; Privat, A.M.; Daulhac, L.; Davin, N.; Mazur, A.; Fialip, J.; Eschalier, A. \& Courteix, C. (2010). Magnesium attenuates chronic hypersensitivity and spinal cord 
NMDA receptor phosphorylation in a rat model of diabetic neuropathic pain. $J$ Physiol, Vol.588, No.Pt 21, 4205-4215.

Rowbotham, M.C.; Goli, V.; Kunz, N.R. \& Lei, D. (2004). Venlafaxine extended release in the treatment of painful diabetic neuropathy: a double-blind, placebo-controlled study. Pain, Vol.110, No.3, 697-706.

Saulino, M.; Burton, A.W.; Danyo, D.A.; Frost, S.; Glanzer, J. \& Solanki, D.R. (2009). Intrathecal ziconotide and baclofen provide pain relief in seven patients with neuropathic pain and spasticity: case reports. Eur J Phys Rehabil Med, Vol.45, No.1, 61-67.

Sawynok, J. \& Reid, A. (2001). Antinociception by tricyclic antidepressants in the rat formalin test: differential effects on different behaviours following systemic and spinal administration. Pain, Vol.93, No.1, 51-59.

Schafers, M.; Sorkin, L.S. \& Sommer, C. (2003). Intramuscular injection of tumor necrosis factor-alpha induces muscle hyperalgesia in rats. Pain, Vol.104, No.3, 579-588.

Schuler, V.; Luscher, C.; Blanchet, C.; Klix, N.; Sansig, G.; Klebs, K.; Schmutz, M.; Heid, J.; Gentry, C.; Urban, L.; Fox, A.; Spooren, W.; Jaton, A.L.; Vigouret, J.; Pozza, M.; Kelly, P.H.; Mosbacher, J.; Froestl, W.; Kaslin, E.; Korn, R.; Bischoff, S.; Kaupmann, K.; van der Putten, H. \& Bettler, B. (2001). Epilepsy, hyperalgesia, impaired memory, and loss of pre- and postsynaptic GABA(B) responses in mice lacking GABA(B(1)). Neuron, Vol.31, No.1, 47-58.

Seltzer, Z.; Dubner, R. \& Shir, Y. (1990). A novel behavioral model of neuropathic pain disorders produced in rats by partial sciatic nerve injury. Pain, Vol.43, No.2, 205218.

Sheen, K. \& Chung, J.M. (1993). Signs of neuropathic pain depend on signals from injured nerve fibers in a rat model. Brain Res, Vol.610, No.1, 62-68.

Shehab, S.A.; Spike, R.C. \& Todd, A.J. (2003). Evidence against cholera toxin B subunit as a reliable tracer for sprouting of primary afferents following peripheral nerve injury. Brain Res, Vol.964, No.2, 218-227.

Shir, Y. \& Seltzer, Z. (1990). A-fibers mediate mechanical hyperesthesia and allodynia and Cfibers mediate thermal hyperalgesia in a new model of causalgiform pain disorders in rats. Neurosci Lett, Vol.115, No.1, 62-67.

Shukla, V.K.; Lemaire, S.; Dumont, M. \& Merali, Z. (1995). N-methyl-D-aspartate receptor antagonist activity and phencyclidine-like behavioral effects of the pentadecapeptide, [Ser1] histogranin. Pharmacol Biochem Behav, Vol.50, No.1, 49-54.

Siddall, P.; Xu, C.L. \& Cousins, M. (1995). Allodynia following traumatic spinal cord injury in the rat. Neuroreport, Vol.6, No.9, 1241-1244.

Siddall, P.J.; McClelland, J.M.; Rutkowski, S.B. \& Cousins, M.J. (2003). A longitudinal study of the prevalence and characteristics of pain in the first 5 years following spinal cord injury. Pain, Vol.103, No.3, 249-257.

Siegan, J.B. \& Sagen, J. (1995). Attenuation of NMDA-induced spinal hypersensitivity by adrenal medullary transplants. Brain Res, Vol.680, No.1-2, 88-98.

Sommer, C. \& Kress, M. (2004). Recent findings on how proinflammatory cytokines cause pain: peripheral mechanisms in inflammatory and neuropathic hyperalgesia. Neurosci Lett, Vol.361, No.1-3, 184-187.

Sorkin, L.S. \& Doom, C.M. (2000). Epineurial application of TNF elicits an acute mechanical hyperalgesia in the awake rat. J Peripher Nerv Syst, Vol.5, No.2, 96-100. 
Staaf, S.; Oerther, S.; Lucas, G.; Mattsson, J.P. \& Ernfors, P. (2009). Differential regulation of TRP channels in a rat model of neuropathic pain. Pain, Vol.144, No.1-2, 187-199.

Sun, H.; Ren, K.; Zhong, C.M.; Ossipov, M.H.; Malan, T.P.; Lai, J. \& Porreca, F. (2001). Nerve injury-induced tactile allodynia is mediated via ascending spinal dorsal column projections. Pain, Vol.90, No.1-2, 105-111.

Sung, B.; Lim, G. \& Mao, J. (2003). Altered expression and uptake activity of spinal glutamate transporters after nerve injury contribute to the pathogenesis of neuropathic pain in rats. J Neurosci, Vol.23, No.7, 2899-2910.

Suzuki, R.; Morcuende, S.; Webber, M.; Hunt, S.P. \& Dickenson, A.H. (2002). Superficial NK1-expressing neurons control spinal excitability through activation of descending pathways. Nat Neurosci, Vol.5, No.12, 1319-1326.

Tal, M. \& Eliav, E. (1996). Abnormal discharge originates at the site of nerve injury in experimental constriction neuropathy (CCI) in the rat. Pain, Vol.64, No.3, 511-518.

Taylor, C.P.; Gee, N.S.; Su, T.Z.; Kocsis, J.D.; Welty, D.F.; Brown, J.P.; Dooley, D.J.; Boden, P. \& Singh, L. (1998). A summary of mechanistic hypotheses of gabapentin pharmacology. Epilepsy Res, Vol.29, No.3, 233-249.

Teichert, R.W.; Jimenez, E.C.; Twede, V.; Watkins, M.; Hollmann, M.; Bulaj, G. \& Olivera, B.M. (2007). Novel conantokins from Conus parius venom are specific antagonists of N-methyl-D-aspartate receptors. J Biol Chem, Vol.282, No.51, 36905-36913.

Ugarte, S.D.; Homanics, G.E.; Firestone, L.L. \& Hammond, D.L. (2000). Sensory thresholds and the antinociceptive effects of GABA receptor agonists in mice lacking the beta3 subunit of the GABA(A) receptor. Neuroscience, Vol.95, No.3, 795-806.

Vierck, C.J., Jr. \& Light, A.R. (1999). Effects of combined hemotoxic and anterolateral spinal lesions on nociceptive sensitivity. Pain, Vol.83, No.3, 447-457.

Wahren, L.K. \& Torebjork, E. (1992). Quantitative sensory tests in patients with neuralgia 11 to 25 years after injury. Pain, Vol.48, No.2, 237-244.

Wakisaka, S.; Kajander, K.C. \& Bennett, G.J. (1991). Increased neuropeptide Y (NPY)-like immunoreactivity in rat sensory neurons following peripheral axotomy. Neurosci Lett, Vol.124, No.2, 200-203.

Walker, K.; Fox, A.J. \& Urban, L.A. (1999). Animal models for pain research. Mol Med Today, Vol.5, No.7, 319-321.

Wallace, M.S.; Rauck, R.; Fisher, R.; Charapata, S.G.; Ellis, D. \& Dissanayake, S. (2008). Intrathecal ziconotide for severe chronic pain: safety and tolerability results of an open-label, long-term trial. Anesth Analg, Vol.106, No.2, 628-637, table of contents.

Wallace, V.C.; Cottrell, D.F.; Brophy, P.J. \& Fleetwood-Walker, S.M. (2003). Focal lysolecithin-induced demyelination of peripheral afferents results in neuropathic pain behavior that is attenuated by cannabinoids. J Neurosci, Vol.23, No.8, 32213233.

Watson, C.P.; Evans, R.J.; Reed, K.; Merskey, H.; Goldsmith, L. \& Warsh, J. (1982). Amitriptyline versus placebo in postherpetic neuralgia. Neurology, Vol.32, No.6, 671-673.

Wood, J.N.; Boorman, J.P.; Okuse, K. \& Baker, M.D. (2004). Voltage-gated sodium channels and pain pathways. J Neurobiol, Vol.61, No.1, 55-71.

Woolf, C.J.; Shortland, P. \& Coggeshall, R.E. (1992). Peripheral nerve injury triggers central sprouting of myelinated afferents. Nature, Vol.355, No.6355, 75-78. 
Wu, G.; Ringkamp, M.; Hartke, T.V.; Murinson, B.B.; Campbell, J.N.; Griffin, J.W. \& Meyer, R.A. (2001). Early onset of spontaneous activity in uninjured C-fiber nociceptors after injury to neighboring nerve fibers. J Neurosci, Vol.21, No.8, RC140.

Xu, X.J.; Hao, J.X.; Aldskogius, H.; Seiger, A. \& Wiesenfeld-Hallin, Z. (1992). Chronic painrelated syndrome in rats after ischemic spinal cord lesion: a possible animal model for pain in patients with spinal cord injury. Pain, Vol.48, No.2, 279-290.

Yezierski, R.P. \& Park, S.H. (1993). The mechanosensitivity of spinal sensory neurons following intraspinal injections of quisqualic acid in the rat. Neurosci Lett, Vol.157, No.1, 115-119.

Yoon, Y.W.; Na, H.S. \& Chung, J.M. (1996). Contributions of injured and intact afferents to neuropathic pain in an experimental rat model. Pain, Vol.64, No.1, 27-36.

Ziegler, E.A.; Magerl, W.; Meyer, R.A. \& Treede, R.D. (1999). Secondary hyperalgesia to punctate mechanical stimuli. Central sensitization to A-fibre nociceptor input. Brain, Vol.122 ( Pt 12), 2245-2257.

Zochodne, D.W. \& Max, M.B. (2003). An old acquaintance: opioids in neuropathic pain. Neurology, Vol.60, No.6, 894-895. 


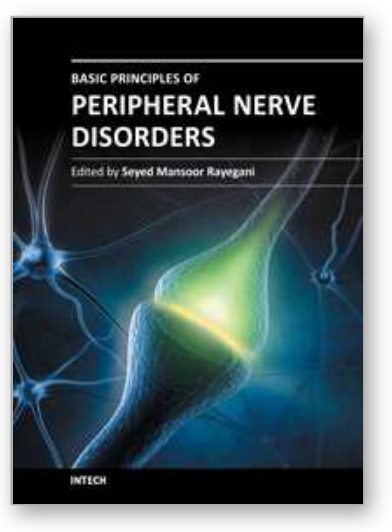

\author{
Basic Principles of Peripheral Nerve Disorders \\ Edited by Dr. Seyed Mansoor Rayegani
}

ISBN 978-953-51-0407-0

Hard cover, 278 pages

Publisher InTech

Published online 28, March, 2012

Published in print edition March, 2012

Peripheral nerve disorders are comprising one of the major clinical topics in neuromusculoskeletal disorders. Sharp nerve injuries, chronic entrapment syndromes, and peripheral neuropathic processes can be classified in this common medical topic. Different aspects of these disorders including anatomy, physiology, pathophysiology, injury mechanisms, and different diagnostic and management methods need to be addressed when discussing this topic. The goal of preparing this book was to gather such pertinent chapters to cover these aspects.

\title{
How to reference
}

In order to correctly reference this scholarly work, feel free to copy and paste the following:

Stanislava Jergova (2012). Neuropathic Pain Following Nerve Injury, Basic Principles of Peripheral Nerve Disorders, Dr. Seyed Mansoor Rayegani (Ed.), ISBN: 978-953-51-0407-0, InTech, Available from: $\mathrm{http}: / /$ www.intechopen.com/books/basic-principles-of-peripheral-nerve-disorders/neuropathic-pain-followingnerve-injury

\section{INTECH}

open science | open minds

\section{InTech Europe}

University Campus STeP Ri

Slavka Krautzeka 83/A

51000 Rijeka, Croatia

Phone: +385 (51) 770447

Fax: +385 (51) 686166

www.intechopen.com

\section{InTech China}

Unit 405, Office Block, Hotel Equatorial Shanghai

No.65, Yan An Road (West), Shanghai, 200040, China

中国上海市延安西路65号上海国际贵都大饭店办公楼405单元

Phone: +86-21-62489820

Fax: $+86-21-62489821$ 
(C) 2012 The Author(s). Licensee IntechOpen. This is an open access article distributed under the terms of the Creative Commons Attribution 3.0 License, which permits unrestricted use, distribution, and reproduction in any medium, provided the original work is properly cited. 